www.scientiaplena.org.br

doi: 10.14808/sci.plena.2019.074811

\title{
Atividades experimentais com arduino abordando fundamentos da cinemática, termometria e eletrodinâmica na escola estadual de ensino médio Dr. Gabriel Sales Pimenta em Marabá (PA)
}

Experimental activities with arduino approaching fundamentals of kinematics, thermometry and electrodynamics at the state high school Dr. Gabriel Sales Pimenta in Marabá (PA)

\author{
J. G. S. Lima Junior ${ }^{1}$; L. M. Gomes²*; E. R. P. de Novais²; F. C. L. Ferreira ${ }^{2}$ \\ ${ }^{1}$ Faculdade de Física/Instituto de Ciências Exatas/Programa Nacional de Mestrado Profissional em Ensino de Física, \\ Universidade Federal do Sul e Sudeste do Pará, 68507-59, Marabá - Pará, Brasil \\ ${ }^{2}$ Faculdade de Física/Instituto de Ciências Exatas, Universidade Federal do Sul e Sudeste do Pará, 68507-59, Marabá \\ - Pará, Brasil \\ *luizmg@unifesspa.edu.br
}

(Recebido em 26 de fevereiro de 2019; aceito em 29 de julho de 2019)

\begin{abstract}
Atualmente, nas aulas de física do ensino médio, salvo raras exceções, observa-se uma disparidade com relação às atividades de ensino aprendizagem em física: de um lado, professores que ensinam fórmulas (receitas) para resolução de problemas, e do outro, estudantes com inúmeras dificuldades na compreensão da maioria dos conteúdos de física. Hoje em dia, torna-se inconcebível a ideia de se fazer ensino sem a inserção de ferramentas computacionais na análise científica ou em atividades experimentais de um modo geral, principalmente quando dessa prática, requer-se uma compreensão ampla sobre os fenômenos envolvidos nessa análise. Acredita-se que o desenvolvimento de atividades utilizando placas de prototipagem assim como o Arduino quer por sua versatilidade, custo, dentre outros, aliadas às teorias de ensino, em especial, voltadas ao ensino de física, talvez seja a linha de pesquisa que tenha dispensado maiores esforços e investimentos nos últimos anos há diversas pesquisas na área disponíveis na literatura. Nesse artigo, apresenta-se os resultados quanto à implementação de atividades experimentais utilizando a placa como ferramenta auxiliar de ensino abordando conteúdos de Cinemática, Termometria e Eletrodinâmica voltadas aos estudantes do ensino médio de uma escola da Rede Pública Estadual do município de Marabá Pará.

Palavras-chave: Ensino de Física, Inovação, Arduino.
\end{abstract}

Currently, in the physics classes of high school, with rare exceptions, there is a disparity with respect to teaching-learning activities in Physics: on the one hand, teachers who teach formulas (recipes) to solve problems, and on the other, students with numerous difficulties in understanding most of the contents of Physics. Nowadays, it becomes inconceivable the idea of teaching without the insertion of computational tools in scientific analysis or in experimental activities in general, especially when this practice requires a broad understanding of the phenomena involved in this analysis. It is believed that the development of activities using prototyping platform as the Arduino for its versatility, cost, among others, allied to teaching theories, in particular, focused on physics teaching, perhaps it is the line of research that has exerted great efforts and investments in recent years - there are several researches in the area available in the literature. In this article, we present the results regarding the implementation of experimental activities using the prototyping platform as an auxiliary teaching tool approaching contents of Kinematics, Thermometry and Electrodynamics aimed at the high school students of a school of the State Public Network of the municipality of Marabá - Pará.

Keywords: Teaching Physics, Innovation, Arduino. 


\section{INTRODUÇÃO}

Hoje em dia, nas aulas de física ministradas no ensino médio, salvo algumas exceções, observase uma disparidade com relação às atividades de ensino aprendizagem. De um lado, professores que ensinam fórmulas para resolução de problemas, e do outro, estudantes com inúmeras dificuldades de aprendizado.

Na maioria das vezes, as atividades experimentais não traduzem os anseios e expectativas para ambos, além do mais, a abstração e a subjetividade em temas complexos tais como são os da física, tornam-se entraves no processo de ensino, principalmente, em se tratando de uma escola contextualizada em um cenário nada animador, em que elementos e práticas de ensino não convergem para um ambiente em que a pluralidade de ideias e o protagonismo estudantil não são prioritários.

Nesse sentido, afirma Rolando e Moreira (1991) [1], que embora exista um número expressivo de professores que as pratique, há ainda um número significativo que se limita ao "giz e quadro negro" ora pela falta de recursos ou espaços necessários para a realização das atividades, ora pela ausência de uma capacitação adequada para esse fim.

Ressalta-se ainda que para a realização das atividades experimentais, estas não precisam, em hipótese alguma, serem condicionadas a bancadas, instrumentos sofisticados ou de alto custo. $\mathrm{O}$ importante é a organização das etapas e conteúdos mantendo-se os objetivos estabelecidos previamente na perspectiva de Borges (2002) [2].

Atualmente, dispõem-se na literatura uma gama de artigos, relatos, dissertações e teses que reforçam a importância das atividades experimentais, em especial, por intermédio das ferramentas computacionais na análise científica utilizadas nas aulas como meio de promover o protagonismo e a formação da cultura científica.

Nessa linha, os Parâmetros Curriculares Nacionais (PCN) enfatizam que o ensino de física pode contribuir sobremaneira com a formação da cultura científica nos estudantes na escola média [3], ou seja, torna-se indissociável a ideia de que o ensino precisa caminhar lado a lado com a tecnologia.

Obviamente, observa-se que há uma dicotomia de interesses: de um lado, alunos ávidos por algo novo com aulas dinâmicas e interativas -, e do outro, professores que embora sejam suscetíveis ao novo, ao interativo, não se emponderam das práticas e metodologias inovadoras de ensino. Nesse escopo, a utilização de plataformas em experimentos torna-se ferramenta aliada à prática docente. É óbvio que por si não contempla toda a magnitude do processo cognitivo envolvido, porém, auxilia-o significativamente.

Nesse artigo, utilizou-se a placa Arduino na confecção dos kits experimentais em função da versatilidade, custo, mobilidade, além, é claro, permitir a leitura simultânea dos dados através dos sensores de forma simples e rápida.

Por fim, a proposta das atividades é levar o aluno à compressão dos conceitos físicos por meio do uso da plataforma Arduino, subsidia-lo nas discussões no âmbito escolar por intermédio das comparações advindas dos dados provenientes nas atividades experimentais e dos dados analíticos aferidos pelos próprios estudantes. Além disso, torna-se imprescindível a fundamentação e validação da proposta com o aporte teórico pedagógico através das teorias de aprendizagem afins e correlacionadas.

\section{FUNDAMENTAÇÃO TEÓRICA}

\subsection{O Arduino}

Basicamente, a placa Arduino surgiu na Itália em 2005 e consiste em uma plataforma de prototipagem de código aberto Open-source baseada na linguagem $\mathrm{C} / \mathrm{C}++$, e em softwares e hardwares livres para as áreas de automação.

Nela é possível adicionar diversos tipos de componentes eletrônicos. Dessa forma, a placa pode ser utilizada como gerenciador automatizado de dispositivos externos na aquisição de dados por intermédio de sensores de entrada e saída. Em termos práticos, é um pequeno computador programável para processar entradas e saídas entre o dispositivo e os componentes que estejam conectados. 
No projeto original voltado aos profissionais de Artes-Plásticas o objetivo era criar ferramentas acessíveis, flexíveis e interativas voltadas à área. Entretanto, devido ao fato de operar com o código aberto "Open-source" disseminou-se no mercado com várias opções de placas a preços acessíveis e nas diversas áreas. Existem outras plataformas de prototipagem, entretanto o Arduino tem se destacado no cenário mundial pela facilidade de programação, versatilidade e baixo custo. No mercado há vários modelos de placas Arduino, porém, as mais utilizadas são a Uno, Leonardo e a Mega. Na Tabela 1 apresentam-se as principais características das placas Arduino.

Tabela 1: Principais características das placas Arduino Uno, Leonardo e Mega.

\begin{tabular}{c|c|c|c}
\hline Placa & Uno & Leonardo & Mega \\
\hline Microcontrolador & ATmega 328 & ATmega 32u4 & ATmega 2560 \\
Tensão de Funcionamento & $5 \mathrm{~V}$ & $5 \mathrm{~V}$ & $5 \mathrm{~V}$ \\
Tensão de Entrada & $6-20 \mathrm{~V}$ & $6-20 \mathrm{~V}$ & $6-20 \mathrm{~V}$ \\
Pinos de Entrada e Saída & 14 & 20 & 54 \\
Entradas Analógicas & 6 & 12 & 16 \\
Flash Memory & $32 \mathrm{~kb}$ & $32 \mathrm{~kb}$ & $256 \mathrm{~kb}$ \\
Velocidade do Clock & $16 \mathrm{MHz}$ & $16 \mathrm{MHz}$ & $16 \mathrm{MHz}$ \\
\hline
\end{tabular}

Como visto na tabela acima, a placa ATmega 2560 R3 compatível apresenta quantidade superior de pinos digitais de entradas e saídas, entradas analógicas e de memória com relação às demais, o que de certa forma amplia a capacidade de processamento e de conexão dos jumpers (Figura 1), motivo pelo qual optou-se em utilizá-la em todos os kits.

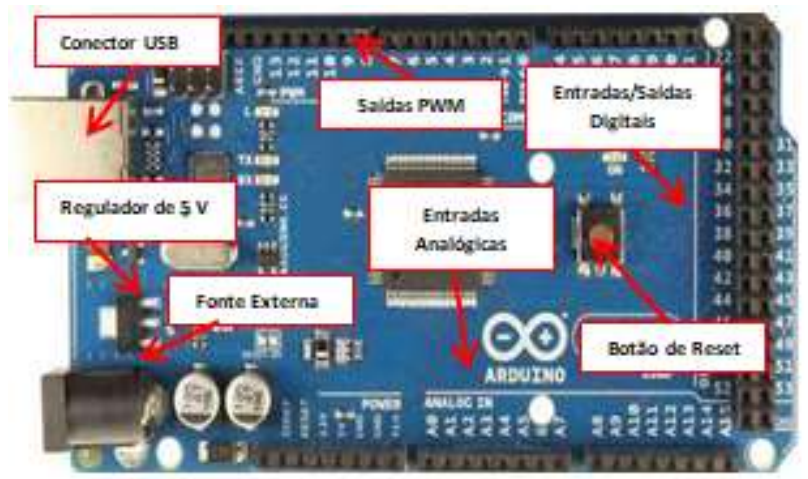

Figura 1: Placa Arduino MEGA 2560 R3 com algumas especificações. Fonte: Os autores.

Quanto à programação do Arduino, é utilizada uma linguagem de programação própria. $\mathrm{O}$ ambiente de desenvolvimento (IDE - Integrated Development Environment) ou Ambiente Integrado de Desenvolvimento baseia-se no ambiente Processing (software de desenvolvimento de desenhos e interface) e pode ser utilizado nos mais diversos sistemas operacionais. Antes de programar torna-se imprescindível configurar o IDE para o modelo de placa a ser utilizada.

Tratando-se da programação no Arduino, o código divide-se em três partes: a primeira delas é a parte destinada à declaração de variáveis; a segunda é a de definição dos parâmetros das portas e pôr fim a terceira parte refere-se ao bloco ou estrutura de comandos.

Existem diversos trabalhos publicados quanto à utilização do Arduino no ensino, que vão desde um simples acendimento de um LED (Light Emitting Diode) até experimentos mais complexos como, por exemplo, um pacote experimental desenvolvido para demonstrar qualitativamente o efeito fotoelétrico e as propriedades elétricas do plasma Silveira (2016) [4].

Inegavelmente, a plataforma Arduino, pelo que foi apresentado até o momento e com base em publicações anteriores, torna-se uma alternativa viável economicamente, e notadamente, como uma ferramenta potencial ao ensino, não somente com relação aos conteúdos de física, mas em diversos outros.

\subsection{A aprendizagem significativa de Ausubel}

A teoria da aprendizagem significativa proposta por Davi Ausubel é uma teoria cognitivista e procura explicar os mecanismos que ocorrem na mente humana com relação ao aprendizado e à estruturação do conhecimento. A Teoria da Aprendizagem Significativa pode contribuir para 
melhorar a compreensão de um conteúdo específico e, segundo Vannucchi (1996) [5], "Superando, desta forma, a aquisição mecânica de fórmulas, equações e expressões físicas que, muitas vezes, os alunos decoram e utilizando sem compreender o seu significado real".

A aprendizagem significativa envolve a aquisição de novos significados e estes, por sua vez, são produtos da aprendizagem significativa. Eles ocorrem na medida em que determinadas ideias, ao serem aprendidas, relacionam-se de forma não-arbitrária e não-literal a alguns conhecimentos relevantes existentes na estrutura cognitiva do aprendiz, afirma Ausubel (1980) [6].

Para o autor, estes conhecimentos relevantes da estrutura cognitiva - a qual se encoram e se reordenam em novos conceitos e ideias que o estudante formula e internaliza, e que servem de suporte para a nova informação, são denominados subsunçores. Sendo assim, na teoria, quando um estudante se depara com um material para estuda-lo é preciso que ele tenha subsunçores em sua estrutura cognitiva, caso contrário, não ocorrerá a aprendizagem significativa.

A Teoria de Ausubel propõe uma estratégia para facilitar a aprendizagem significativa, manipulando a estrutura cognitiva do aprendiz. A estratégia envolve o uso de materiais introdutórios adequados, claros e estáveis, os quais são denominados de organizadores prévios.

Os organizadores prévios são "introduzidos antes do conteúdo de aprendizagem com a função de gerar estruturas cognitivas para a aprendizagem e devem ser apresentados em um nível de abstração mais elevado, de maior generalidade e inclusão do que o material a ser aprendido" afirma Ausubel (2003) [7].

Dessa forma, conclui-se que os organizadores prévios funcionam como pontes cognitivas, cuja atribuição é contribuir para que o estudante possa superar o limite entre o conhecimento prévio existente e o conhecimento a ser aprendido.

Os conceitos propostos por Ausubel, de subsunçores e organizadores prévios, uma vez que incorporados às atividades experimentais, em especial às atividades voltadas ao ensino de física, podem servir como ferramentas metodológicas interessantes ao ensino, além disso, fornecem parâmetros que reforçam a aquisição de conhecimento.

\subsection{A teoria do Desenvolvimento Intelectual de Bruner}

Teórico conhecido por sua polêmica afirmação "é possível ensinar qualquer assunto, de uma maneira intelectualmente honesta, a qualquer criança em qualquer estágio de desenvolvimento" Moreira (1999) [8], Jerome Bruner propõe em sua teoria que o mais relevante em determinada matéria ou disciplina é a sua estrutura, suas ideias e relações fundamentais. Obviamente, o autor refere-se à possibilidade de ensino aos estudantes, desde que se levassem em contas as etapas do desenvolvimento intelectual de cada um.

Para o autor, o processo da descoberta por parte dos estudantes, é um processo de ensino. Este, através da exploração de alternativas e de um currículo em espiral, é capaz de oportunizar ao estudante rever os tópicos de diferentes níveis de profundidade [8]. Desse modo, propicia ao estudante o acesso e a participação no processo de aprendizagem. Em outras palavras, a aprendizagem por descoberta ocorre quando o professor cria um ambiente, ou conteúdo, que favoreçam a aprendizagem. Nesse ambiente, o professor apresenta as ferramentas necessárias aos estudantes para o aprendizado.

Para Bruner, "a ideia de desenvolvimento intelectual ocupa lugar fundamental em sua teoria" [8]. Assim, o desenvolvimento intelectual caracteriza-se por independência crescente da resposta em relação à natureza imediata do estímulo, ou seja, uma vez estimulado a pensar sobre determinado assunto, o aprendiz desenvolve suas aptidões cognitivas. $\mathrm{O}$ desenvolvimento intelectual baseia-se em absorver eventos, em um sistema de armazenamento que corresponde ao meio ambiente, nesse sentido, um ambiente favorável ao aprendizado, com elementos e ferramentas novas de ensino propiciam a aprendizagem e consequentemente o desenvolvimento do intelecto do estudante.

O desenvolvimento intelectual é caracterizado por crescente capacidade para lidar com alternativas simultaneamente, atender a várias sequencias ao mesmo tempo, e distribuir tempo e atenção, de maneira apropriada, a todas essas demandas múltiplas, por fim o autor refere-se ao contato direto do professor com os estudantes na atenção efetiva e simultânea das demandas que surgem durante a aula ou durante a experimentação.

Na visão de Bruner, existem três modos de representação pelos quais passam os indivíduos, os quais são a representação ativa, a representação icônica e a representação simbólica [8]. Na 
representação ativa desenvolve-se a inteligência prática, como consequência do contato do aprendiz com os objetos e com os problemas de ação que o meio lhe propicia. Na representação icônica o aprendiz, após visualizar os objetos, utiliza imagens mentais que representam tais objetos - essa representação independe da ação. Finalmente, na representação simbólica o aprendiz consegue representar as coisas por símbolos, abstratamente. Por exemplo, ao visualizar um circuito elétrico, o aluno intuitivamente, desde que seja instruído previamente, é capaz de reconhecer o tipo do circuito RC (resistor/capacitor) ou RL (resistor/indutor), por intermédio dos símbolos associados no circuito.

\subsection{A Transposição Didática como ferramenta de ensino}

Hoje em dia não é tarefa fácil ensinar, em especial, o ensino de disciplinas complexas como as que compõem o currículo em Física. Recheadas de conceitos abstratos em sua maior parte, de definições um tanto quanto ortodoxas - que exigem do estudante uma concepção plausível a respeito, e que embora o professor busque meios para fazê-lo, nem sempre os objetivos de aprendizagem são alcançados.

Apesar das controvérsias sobre a temática, para a maioria dos pesquisadores, a respeito das competências, associam-nas a uma mobilização de recursos cognitivos aplicados a situações distintas que vão além da sala de aula, ou seja, transpor o mesmo conteúdo por meio de outras práticas didáticas a exemplo, a utilização do laboratório didático por intermédio da transposição didática.

Ressalta-se o fato de que a transposição didática não é em hipótese alguma, uma ferramenta de ensino cujo objetivo seja a simplificação do conhecimento. Essa é uma interpretação equivocada, por apresentar o processo complexo do saber de forma trivial. O termo "saber", que trata o autor, serve para designar o objeto sujeito a transformações. Como ferramenta de análise do processo de transformação do saber, a transposição didática estabelece três níveis para o saber os quais são o saber sábio (savoir savant), o saber a ensinar (savoir à enseigner) e o saber ensinado (savoir enseigné). Estes grupos de diferentes saberes, porém com elementos comuns fazem parte de um ambiente mais amplo, que se interligam e coexistem denominados de noosfera Chevallard (1999) [9].

$\mathrm{Na}$ troca entre os saberes ocorre o processo de transposição didática. O processo de transformação do "saber sábio" para o "saber a ensinar", corresponde a transposição didática externa. É nessa fase que o conhecimento científico é reestruturado para uma linguagem mais simples, acessível para os estudantes. No processo de transformação do "saber a ensinar" para o "saber ensinado", ocorre a Transposição Didática Interna. Nesse momento, o conhecimento é diluído no interior do espaço escolar (sala de aula, laboratório didático, ou em qualquer outro espaço pedagógico).

O método experimental pode ser analisado e submetido às regras de transposição didática, uma vez que se percebem elementos passíveis de avaliação Além do mais, ao estruturar-se o laboratório didático no espaço escolar, o método experimental inclui-se ao processo de ensino da escola, desde forma, fortalece a concepção empirista de ciência [10]. Em suma, acredita-se que a transposição didática serve como instrumento de análise do laboratório didático em função da possibilidade de se verificar as evidências de aprendizagem advindas das atividades experimentais, além é claro, de que o método experimental utilizado no processo assume a conotação de "saber sábio" e consequentemente transforma-se em "saber a ensinar" à medida que o professor assume o papel de mediador no processo.

\section{MATERIAL E MÉTODOS}

A escola estadual de Ensino Médio Dr. Gabriel Sales Pimenta, localiza-se distante do núcleo urbano de Marabá, a uma distância de cerca de 30 km, em Morada Nova, Marabá (PA). De localização privilegiada em função da confluência de acesso por via rodoviária às outras cidades, atende atualmente 850 alunos da zona urbana e rural nos três turnos disponíveis. A oferta de ensino é em tempo integral nas primeiras e segundas séries, entretanto, às terceiras séries disponíveis não são contempladas com a mesma modalidade de ensino.

O público alvo do trabalho foram 03 (três) turmas da escola. Ao todo participaram 80 alunos das três séries, sendo 25 alunos da $1^{\mathrm{a}}$ série, 25 alunos da $2^{\mathrm{a}}$ série e 30 alunos da $3^{\mathrm{a}}$ série. As turmas 
foram submetidas aos mesmos instrumentos de avaliação (questionários avaliativos) e aulas expositivas delineadas por sequências didáticas específicas. Entretanto, em cada turma foram abordados conteúdos e aplicados roteiros distintos. Para a coleta de dados, aplicou-se o Termo de Assentimento Livre e Esclarecido (TCLE) com os envolvidos na pesquisa.

\subsection{Atividade Experimental I - Cinemática: MRU e MRUV}

Em um primeiro momento os alunos foram submetidos ao questionário avaliativo I (cerca de 10 minutos), com o intuito de verificar o conhecimento deles a respeito dos assuntos que seriam abordados posteriormente, tanto nas aulas expositivas, quanto nas atividades experimentais com o Arduino. Após esse momento, procedeu-se à explanação do conteúdo propriamente dito. $\mathrm{Na} 1^{\mathrm{a}}$ série foram abordados os conteúdos de Cinemática, em especial, sobre o Movimento Retilíneo Uniforme (MRU) e suas características e sobre o Movimento Retilíneo Uniforme Variado (MRUV). No MRU foram abordados os conceitos elementares sobre velocidade e no MRUV abordaram-se os conceitos sobre a velocidade e aceleração gravitacional através do movimento queda livre.

A bancada foi construída em MDF (Figura 2), medindo $175 \mathrm{~cm}$ de comprimento. Ela foi utilizada nas duas atividades, entretanto, o Arduino teve programação específica para cada caso. Nas primeiras medições, foram aferidas a velocidade do móvel (carrinho), desprezando-se a resistência, a fim de verificar se a velocidade era constante (MRU). No caso do experimento de queda livre (Figura 3), utilizou-se a mesma bancada, porém, na posição vertical, cujo objetivo foi verificar a aceleração gravitacional de dois móveis (esfera de aço e de isopor).

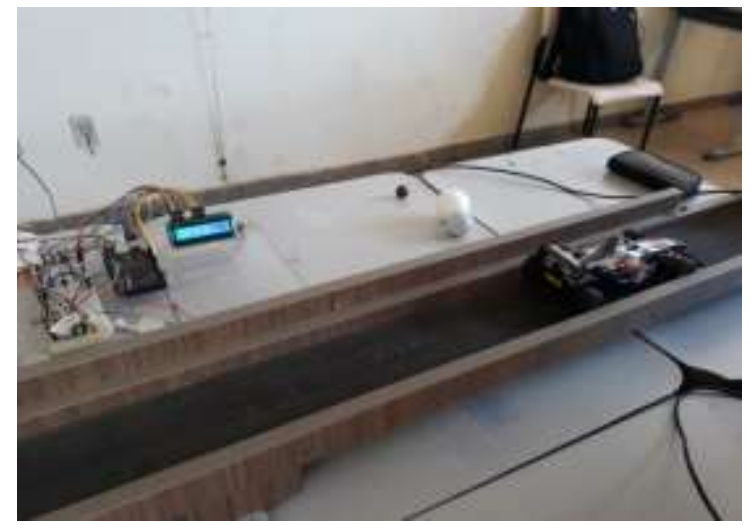

Figura 2: Bancada, plataforma de polietileno e utensílios utilizados no Experimento I. Fonte: Os autores.

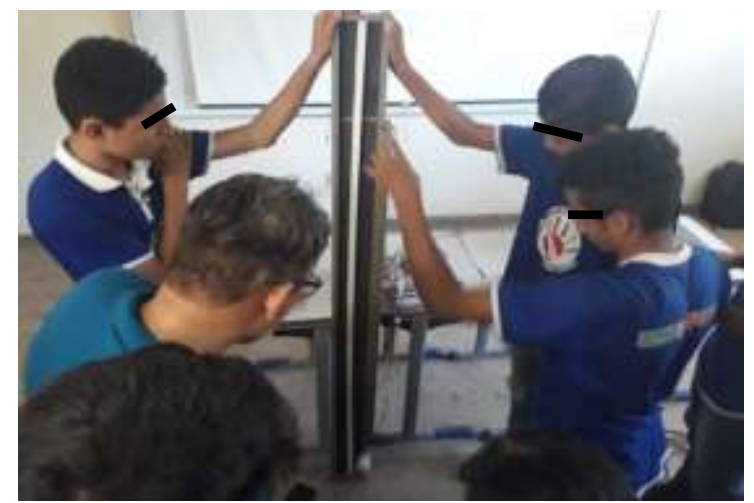

Figura 3: Experimento de Queda Livre. Fonte: Os autores.

A coleta das informações para o Arduino foi realizada por meio de dois sensores ópticos de reflexão modelo TCRT 5000, com comprimento de onda emissor de $950 \mathrm{~nm}$, com tipo de detecção fototransistor com detecção máxima de $25 \mathrm{~mm}$.

Em um segundo momento, os estudantes foram submetidos ao preenchimento do questionário avaliativo II (10 minutos), cujo objetivo foi obter a resposta deles acerca da atividade experimental, a relação com o conteúdo, dentre outros. Por fim, a turma foi dividida em 05 (cinco) grupos compostos de cinco alunos (grupos A, B, C, D e E). Cada grupo (de posse dos dados e medições), respondeu de forma dissertativa o questionário de aprendizagem. As questões tratavam de 
perguntas acerca dos dados apresentados pelo Arduino (cerca de 20 minutos) e as relações com os resultados obtidos analiticamente.

\subsection{Atividade Experimental II - Termometria: Escalas Termométricas}

Inicialmente, a turma de $2^{\mathrm{a}}$ série foi submetida ao questionário avaliativo I (por cerca de 10 minutos). De forma análoga à atividade anterior, o objetivo principal foi verificar a compreensão da turma sobre os assuntos que seriam abordados posteriormente nas aulas expositivas e por meio da realização das atividades experimentais. $\mathrm{Na} 2^{\mathrm{a}}$ série foram abordados os conteúdos sobre Termometria, especificamente acerca das escolas termométricas Celsius e Fahrenheit, zero absoluto, calor versus temperatura, dentre outros. Após essa etapa, os alunos foram realizar a atividade experimental em grupos na qual consistia na medição das temperaturas ambiente, verificação da temperatura da água em processo de ebulição e temperatura da água gelada.

Nesse experimento (Figura 4), utilizou-se o sensor de temperatura à prova d'água modelo DS18B20, com faixa de medição de temperatura em torno de $-55^{\circ} \mathrm{C} \mathrm{a}+125{ }^{\circ} \mathrm{C}$ e precisão de \pm $0,5^{\circ} \mathrm{C}$ e tensão de operação de 3,0 a $5,5 \mathrm{~V}$.

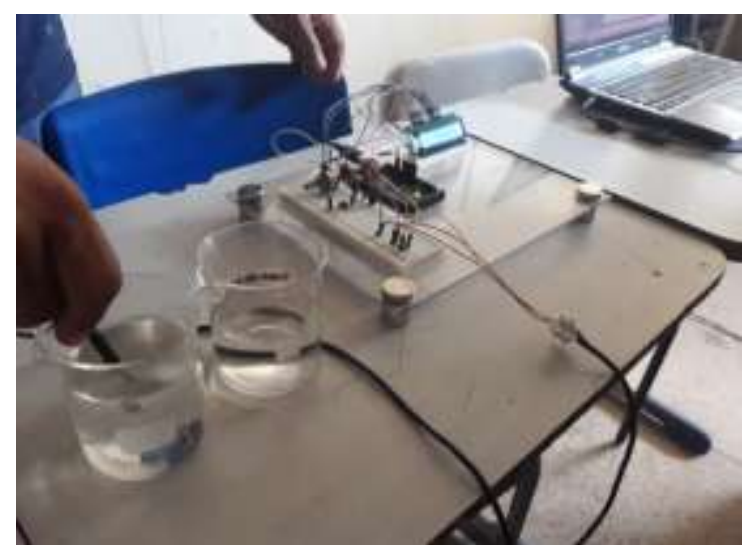

Figura 4: Plataforma de polietileno e medição da temperatura da água no experimento II. Fonte: Os autores.

Posteriormente, foi distribuído aos alunos o questionário avaliativo II para preenchimento (10 minutos), cujo objetivo foi obter a compreensão deles sobre a atividade experimental. Ao final a turma foi dividida em cinco grupos (A, B , C, D e E), formados por cinco alunos em cada grupo. Nesse momento, cada grupo apresentou entre os pares os resultados obtidos no experimento e as observações foram registradas no questionário de aprendizagem em grupo (cerca de 20 minutos de discussão), assim como, os dados obtidos analiticamente foram correlacionados com os resultados apresentados pelo Arduino.

\subsection{Atividade Experimental III - Eletrodinâmica: Corrente e Tensão Elétrica}

A turma de $3^{\text {a }}$ série (Figura 5) foi submetida ao preenchimento do questionário avaliativo I (aproximadamente em 10 minutos). Analogamente, o objetivo primordial desse instrumento de avaliação foi verificar o entendimento dos estudantes sobre os assuntos que seriam abordados nas aulas expositivas e nas atividades experimentais. Os conteúdos abordados na $3^{\mathrm{a}}$ série foram a respeito de corrente e tensão elétrica, embora, foram tratados outros conceitos tais como resistência, potência e a Lei de Ohm. Em seguida, os alunos foram realizar o experimento.

Nesse experimento, utilizou-se os sensores de Tensão AC entrada 127/220 Volts e o sensor de corrente não invasivo 100A-50 mA SCT-013. O sensor de tensão GBK AC 127/220 Volts aceita na entrada uma tensão de 0 a $220 \mathrm{~V}$, além disso, o sensor possui um optoacoplador que assegura o isolamento da tensão $\mathrm{AC}$ na entrada, resistor pull down para garantir que a leitura não flutue e um capacitor para estabilizar a saída. Quanto ao sensor de corrente não invasivo de $100 \mathrm{~A}-50 \mathrm{~mA}$ possui um dielétrico de $6000 \mathrm{~V} / \mathrm{min}$ e trabalha com uma temperatura entre $-25^{\circ} \mathrm{C}$ a $+70^{\circ} \mathrm{C}$.

Ao término das medições, a turma foi dividida em cinco grupos (A, B, C, D e E), formados por cinco alunos em cada grupo. Nesse momento, cada grupo apresentou entre os pares os resultados obtidos no experimento e as observações foram registradas no questionário de aprendizagem em 
grupo (cerca de 20 minutos de discussão), bem como, os dados obtidos analiticamente foram correlacionados com os resultados apresentados pelo Arduino de forma análoga as demais atividades experimentais.

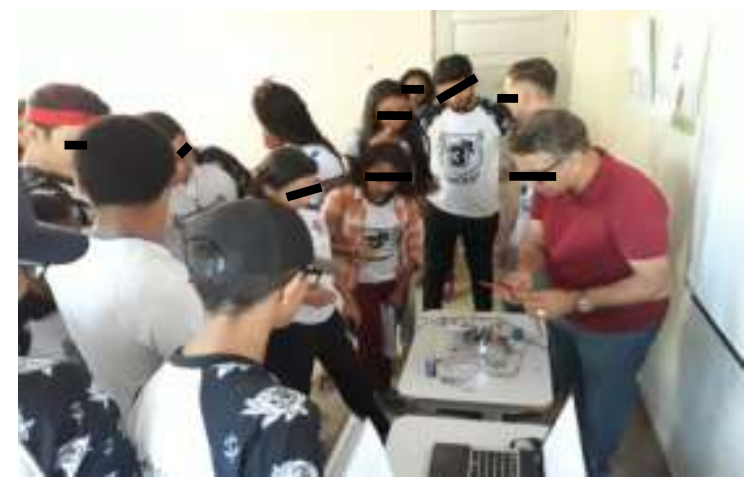

Figura 5: Montagem e realização do Experimento III. Fonte: os autores.

\section{RESULTADOS E DISCUSSÃO}

Após a realização das atividades experimentais, cada turma foi dividida em grupos com o objetivo de compartilhar os resultados obtidos com o uso das bancadas, além de compará-los com os resultados teóricos por intermédio do Questionário Avaliativo de Aprendizagem em Grupo. Na $1^{\mathrm{a}}$ e segunda séries os estudantes foram divididos em cinco grupos, já os alunos da $3^{\mathrm{a}}$ série foram divididos em seis grupos.

\subsection{Resultados da Atividade Experimental I - Cinemática: MRU e MRUV}

Esse experimento foi divido em duas partes: a primeira delas foi à aferição dos parâmetros de velocidade do carrinho em movimento ao longo da trajetória retilínea desprezando-se a resistência do ar e a segunda parte a verificação da velocidade final de impacto em queda livre e os valores aproximados da aceleração gravitacional. Os sensores foram posicionados no início da trajetória e ao final a distância fixa entre os sensores foi de $125 \mathrm{~cm}$.

Os alunos registraram os resultados compartilharam através dos colegas do grupo de discussão os resultados e socializaram os resultados para os demais grupos (Tabela 2).

Tabela 2: Dados do Experimento MRU.

\begin{tabular}{c|c|c|c}
\hline \multirow{2}{*}{ Grupos } & \multicolumn{3}{|c}{ Dados da Atividade Experimental I - Cinemática: MRU } \\
\cline { 2 - 4 } & Velocidade $(\mathbf{c m} / \mathbf{s})$ & Tempo $(\mathbf{s})$ & Deslocamento $(\mathbf{c m})$ \\
\hline Grupo A & 183,2 & 0,68 & 124,57 \\
Grupo B & 181,0 & 0,69 & 124,89 \\
Grupo C & 192,3 & 0,65 & 124,99 \\
Grupo D & 186,0 & 0,67 & 124,62 \\
Grupo E & 175,5 & 0,71 & 124,60 \\
\hline
\end{tabular}

Para efeito de cálculo solicitou-se aos alunos utilizar a função horária da posição conforme Resnick et al. (2005) [11], dada por:

$$
x(t)=x_{0}+v t
$$

Onde $x$ é a posição do carrinho, $x_{0}$ é a posição inicial, $v$ a velocidade e $t$ o instante de tempo. Após a apresentação dos resultados por todos os alunos por entender que no MRU a velocidade do carrinho é constante estabeleceram a média de velocidade para o carrinho 183,6 cm/s. Com respeito às diferenças entre as medições, os alunos entenderam que se deve ao fato dos sensores apresentarem percentuais mínimos de erro entre as medidas, o professor solicitou aos alunos que calculassem esse percentual de erro entre os intervalos de tempo e a resposta foi em torno $0,957 \%$ de erro, ou seja, quase $1 \%$ em relação aos intervalos e as velocidades. 
Na segunda parte do experimento, utilizou-se a mesma bancada, entretanto, na posição vertical com intuito de medir-se a velocidade de impacto das esferas de aço e isopor em queda livre, bem como os valores aproximados da aceleração gravitacional desprezando-se a resistência do ar. Os dados obtidos foram registrados na Tabela 3.

Tabela 3: Dados do Experimento MRUV.

\begin{tabular}{c|c|c|c}
\hline \multirow{2}{*}{ Grupos } & \multicolumn{3}{|c}{ Dados da Atividade Experimental I - Cinemática: MRUV } \\
\cline { 2 - 4 } & Velocidade (cm/s) & Tempo $(\mathbf{s})$ & $\mathbf{g}\left(\mathbf{c m} / \mathbf{s}^{2}\right)$ \\
\hline Grupo A & 495,05 & 0,505 & 980,29 \\
Grupo B & 494,07 & 0,506 & 976,42 \\
Grupo C & 494,07 & 0,506 & 976,42 \\
Grupo D & 493,09 & 0,507 & 972,57 \\
Grupo E & 492,12 & 0,508 & 968,75 \\
\hline
\end{tabular}

A Tabela 3 mostra os dados obtidos durante o experimento de queda livre utilizando os sensores do Arduino. Para efeito de cálculo, utilizou-se como parâmetro a altura de $125 \mathrm{~cm}$ do aparato experimental e a velocidade inicial das esferas nula. Para análise dos parâmetros observados no experimento de Queda Livre os estudantes utilizaram as seguintes equações [11]:

$$
g(t)=\frac{2 h}{t^{2}}
$$

A equação 02 foi utilizada para a verificação da aceleração gravitacional em que $h$ indica a altura em centímetros e $t$ o tempo em segundos.

Para efeito de verificação da velocidade de impacto em Queda Livre utilizou-se a equação de Torricelli aplicada ao MRUV [11].

$$
v^{2}=v_{0}^{2}+2 g h
$$

Como mencionado anteriormente, a velocidade inicial $v_{0}^{2}$ das esferas foi considerada nula. Utilizando-se a equação 03 , os alunos simularam o valor teórico para velocidade final de impacto considerando a altura do anteparo em $125 \mathrm{~cm}$ e constataram algo em torno de $v=495,22 \mathrm{~cm} / \mathrm{s}$ para efeito de correlação com os dados obtidos experimentalmente, utilizou-se a aceleração gravitacional $\mathrm{g}=981 \mathrm{~cm} / \mathrm{s}^{2}$.

A velocidade final de impacto como esperado no MRUV não foi constante. Para efeito de análise da aceleração gravitacional verificou-se que a média foi de $g=974,89 \mathrm{~cm} / \mathrm{s}^{2}$, ou seja, considerando a margem de erro em torno $0,993 \%$ - isto é, quase $1 \%$ de erro foi possível verificar a relação entre o valor da aceleração gravitacional teórica e experimentalmente. [11].

Para a obtenção do tempo teórico de queda das esferas os alunos utilizaram a equação a seguir

$$
t=\sqrt{\frac{2 h}{g}}
$$

Na equação 04 a altura $h$ foi dada em centímetros e a aceleração gravitacional $g=981 \mathrm{~cm} / \mathrm{s}^{2}$.

Os resultados obtidos foram comparados teoricamente, isso propiciou aos estudantes uma análise criteriosa das informações enriquecendo de forma satisfatória as discussões sobre esses resultados, obviamente, considerando as margens de erro do Arduino. Além disso, os alunos ao coletarem as informações, ao manipularem a bancada, sentiram-se parte de todo o processo de aprendizagem. Quando interpelados no questionário a respeito do experimento, a resposta foi enfática, conforme consta na Figura 6, 90\% dos alunos o experimento apresentou evidências significativas sobre o MRU e o movimento de Queda Livre dos corpos. 


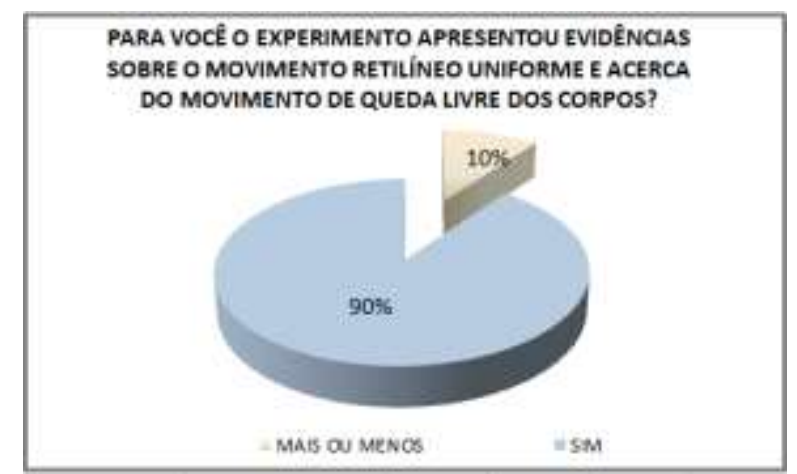

Figura 6: Resposta da turma com relação às evidências de aprendizagem.

\subsection{Resultados da Atividade Experimental II Termometria: Escalas Termométricas}

Nesse experimento, os alunos verificaram as temperaturas do ponto de fusão e ebulição da água, a temperatura ambiente, utilizando um sensor de temperatura acoplado ao Arduino e um termômetro clínico disponível no laboratório da escola para comparar os resultados.

Os alunos registraram as medições e em seguida compartilharam com os colegas em grupos de discussão, além disso, verificaram analiticamente os resultados apresentados pelo Arduino (Tabela 4).

Tabela 4: Dados do Experimento Termometria.

\begin{tabular}{l|c|c|c|c|c|c}
\hline \multirow{2}{*}{ Grupos } & \multicolumn{5}{|c}{ Dados da Atividade Experimental II - Termometria } \\
\cline { 2 - 7 } & \multicolumn{2}{|c|}{ Sensor de Temperatura $\left({ }^{\mathbf{0}} \mathbf{C}\right)$} & \multicolumn{3}{c}{ Termômetro Clínico $\left({ }^{\circ} \mathbf{C}\right)$} \\
\cline { 2 - 7 } & Fusão & Ebulição & Ambiente & Fusão & Ebulição & Ambiente \\
\hline Grupo A & 17,5 & 89,2 & 27,0 & 15,5 & 82,2 & 28,2 \\
Grupo B & 15,2 & 78,2 & 26,5 & 15,2 & 80,5 & 27,4 \\
Grupo C & 16,5 & 83,7 & 25,4 & 15,7 & 82,6 & 26,1 \\
Grupo D & 18,2 & 92,4 & 28,9 & 17,8 & 91,8 & 27,7 \\
Grupo E & 17,4 & 90,5 & 30,5 & 17,2 & 88,7 & 29,8 \\
\hline
\end{tabular}

Um dos objetivos desse experimento, é levar o aluno a refletir sobre as variações de temperatura em diferentes ambientes ou substâncias de modo que lhe permita estabelecer conexões com outras escalas termométricas no caso, abordou-se também a respeito da escala Fahrenheit.

De posse com os dados, os estudantes reuniram-se em grupos de discussão com intuito de verificar analiticamente as informações em outras escalas termométricas. Quando indagados via questionário sobre as evidências de aprendizagem advindas do experimento, a maioria dos estudantes (cerca de 80\%, Figura 7) afirmou que o experimento contribuiu para seu aprendizado.

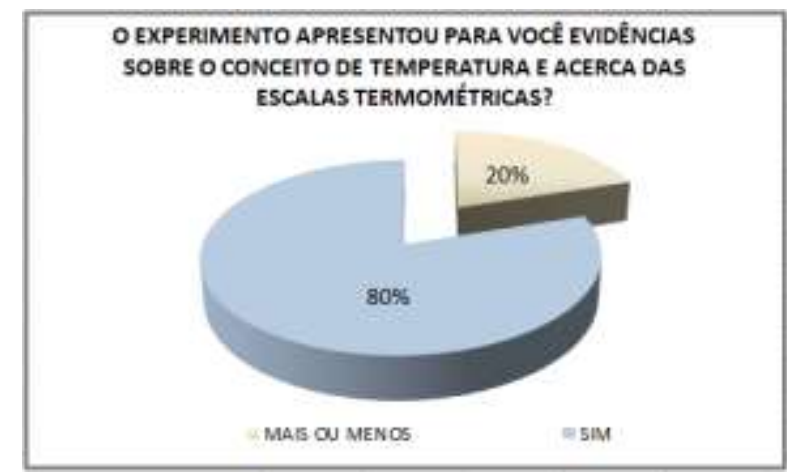

Figura 7. Resposta da turma com relação às evidências de aprendizagem.

\subsection{Resultados da Atividade Experimental III - Eletrodinâmica: Corrente e Tensão Elétrica}

Nessa atividade os estudantes da $3^{\mathrm{a}}$ série utilizaram o Arduino para medições de tensão, corrente elétrica e resistência utilizando sensores específicos para esse fim - os sensores de tensão AC entrada 127/220 Volts e o sensor de corrente não invasivo 100A-50 mA (Tabela 5). 
Em função da reforma da escola no momento das atividades, optou-se por medir-se apenas a tensão e corrente das salas de aula e em uma pilha, não se expandindo para área externa - cabos de força, sistema de refrigeração, padrão elétrico, dentre outros.

Tabela 5. Dados do Experimento em Eletrodinâmica.

\begin{tabular}{c|c|c|c|c}
\hline \multirow{2}{*}{ Grupos } & \multicolumn{3}{|c}{ Dados da Atividade Experimental III - Eletrodinâmica } \\
\cline { 2 - 5 } & \multicolumn{2}{|c}{ Tensão (Volts) } & \multicolumn{2}{c}{ Corrente (Ampères) } \\
\cline { 2 - 5 } & Rede Elétrica & Pilha & Rede Elétrica & Pilha (mA) \\
\hline Grupo A & 114 & 1,4 & 18 & 112 \\
Grupo B & 122 & 1,3 & 14 & 115 \\
Grupo C & 109 & 1,2 & 19 & 115 \\
Grupo D & 125 & 1,3 & 12 & 114 \\
Grupo E & 121 & 1,4 & 14 & 112 \\
Grupo F & 124 & 1,4 & 11 & 112 \\
\hline
\end{tabular}

As medições da voltagem foram em diferentes tomadas e salas. A tabela 5 apresenta de modo sucinto, as informações coletadas pelos alunos por intermédio do Arduino. O objetivo dessa atividade experimental é conduzir o estudante a compreensão das variações de tensão sofridas na rede elétrica por se tratar de uma corrente alternada, e comparar, no caso da pilha elétrica, os dados fornecidos pelo fabricante. Para a concessionária, a corrente máxima associada à tensão máxima de 127 Volts margeia em 20 Ampères, isso significa que pelas medições do Arduino existe uma taxa de aproximação satisfatória nas medições realizadas pelos estudantes.

A tensão média associada no experimento em diferentes pontos elétricos ficou em torno de $U=$ 119,27 volts e a corrente alternada $i=14,67 \mathrm{~A}$, no caso da pilha elétrica, a tensão média ficou em $U=1,33$ Volts e a corrente $i=113,33 \mathrm{~mA}$. Na análise realizada pelos estudantes constatou que para a tensão e corrente conforme os dados fornecidos pela concessionária de energia existem uma margem de erro medida pelo Arduino em torno de $0,73 \%$ para corrente e 0,93 para tensão. No caso da pilha, os dados fornecidos pelo fabricante para a medição da tensão $0,87 \%$ de erro e para a corrente $0,98 \%$ - cerca de $1 \%$ de margem de erro na média.

Para efeitos do cálculo da resistência elétrica e verificação da lei de Ohm, utilizou-se a equação Doca (2013) [12]:

$$
R=\frac{U}{i}
$$

Na equação 05 acima, $U$ é a diferença de potencial (ddp) ou tensão elétrica dada em Volts e $i$ significa a corrente elétrica associada dada em Ampères. A unidade de medida da resistência elétrica é o "ohm", cujo símbolo é dado pela letra grega $\Omega$. Obviamente, pelas medições alternadas de voltagem, ficou claro para os alunos que a resistência elétrica associada à rede elétrica não condiz com a Lei de Ohm, a resistência em todas as medições foram distintas, com isso, a Lei de Ohm não pode ser verificada. Quando questionados sobre o conjunto de evidências de aprendizagem observadas no experimento, os alunos responderam via questionário conforme Figura 8.

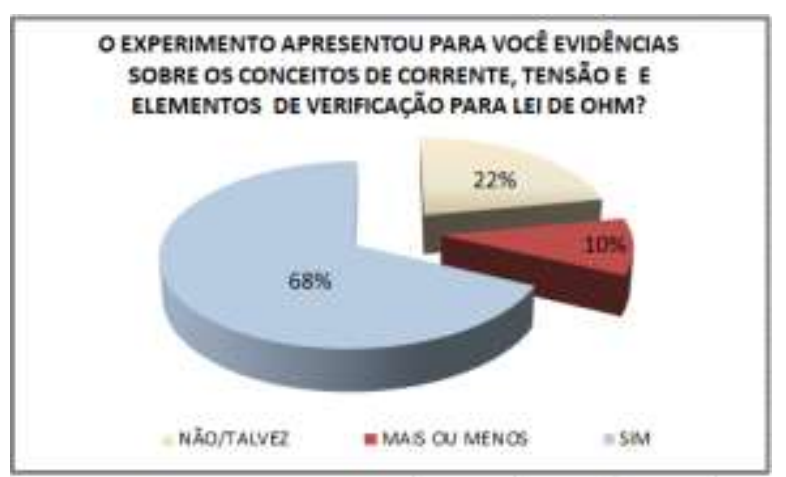

Figura 8. Resposta da turma da $3^{a}$ série com relação às evidências de aprendizagem.

Em última análise, verificou-se por intermédio dos questionários avaliativos que para a maioria dos alunos houve compreensão dos fenômenos observados utilizando a plataforma (Figura 9). 


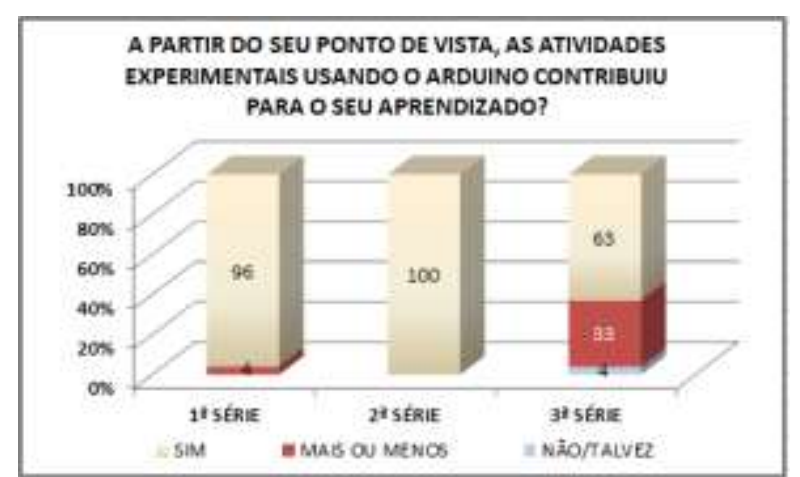

Figura 9. Resultado de satisfação de aprendizagem das três séries do ensino médio.

Um ponto importante na análise da Figura 9, em especial, na $3^{\text {a }}$ série verifica-se que $33 \%$ dos alunos discordaram que as atividades realizadas utilizando-se o Arduino contribuíram com o aprendizado. Nesse ponto, acredita-se que em função das terceiras séries da escola não serem contempladas com o regime de ensino em tempo integral não houve tempo hábil para que alguns alunos desenvolvessem as atividades propostas constantes nos roteiros do experimento, o que de certa forma dificultou o aprendizado de alguns.

\section{CONCLUSÃO}

A proposta desse trabalho o desenvolvimento dos kits experimentais para as três séries do Ensino Médio da Escola Dr. Gabriel Sales Pimenta utilizando o Arduino como plataforma, foi possibilitar ao professor da escola e da rede pública desenvolver as habilidades do docente nessa área, além disso, capacitá-lo em sua prática pedagógica com a diversificação didática de ensino com o uso de novas tecnologias e possibilitar a expectativa de que o docente desenvolva outros materiais com conteúdo distintos, porém com a mesma proposta didático-metodológica. No campo cognitivo, a implementação do material demonstrou que a proposta da aplicação das atividades experimentais nas aulas é interessante para os alunos.

Em todo o processo, observou-se a interação e o protagonismo dos alunos tanto na realização e coleta dos dados quanto na verificação e discussão em grupo dos resultados obtidos. Além disso, verificou-se em todo o processo de ensino a consonância entre as teorias de aprendizagem que fundamentam a proposta com elementos atitudinais e comportamentais dos estudantes, o "aprender fazendo" da teoria do desenvolvimento intelectual de Bruner, a atuação dos organizadores prévios de Ausubel e os fatores que influenciam na transposição didática foram notórios.

Ainda, convém destacar que o compartilhamento dessas informações com todos os profissionais da área de ensino e não somente professores de física, permite que professores de outras áreas de atuação disseminem a proposta entre seus pares. O bom desempenho dos estudantes nas atividades verificado por intermédio dos questionários avaliativos motiva professores e alunos a continuar a disseminação e divulgação da proposta metodológica.

A análise dos fenômenos envolvidos nos experimentos foi registrada nos questionários e em apontamentos individuais, o que de certa forma possibilitou a correlação das informações fornecidas pelo Arduino com os dados encontrados teoricamente e dessa forma foi possível à verificação de percentuais de erros nas medições.

Por fim, sugerem-se aos demais professores e profissionais da área de ensino, promover o desenvolvimento de outros kits experimentais na área ou áreas afins com intuito de disseminar a metodologia e sua eficácia no processo de aprendizagem.

\section{AGRADECIMENTOS}

A CAPES pelo apoio financeiro ao primeiro autor, sem o qual não seria possível o desenvolvimento dessa pesquisa.

\section{REFERÊNCIAS BIBLIOGRÁFICAS}

1., Rolando AXT, Moreira MA. O ensino experimental e a questão do equipamento de baixo custo. Laboratory teaching and the low-cost equipment issue. Rev Ensino Física 1991 Dez;13:97-103. 
2. Borges AT. Novos rumos para o laboratório escolar de ciências. Caderno Brasileiro de Ensino de Física. 2002 Dez;19(3):291-313.

3. Brasil. Ministério da Educação. Secretaria de Educação Média e Tecnológica. Parâmetros Curriculares Nacionais. Ensino Médio. Brasília: MEC, 2000.

4. Silveira S. Desenvolvimento de um Kit Experimental com Arduino para o Ensino de Física Moderna no Ensino Médio (dissertação mestrado profissional). Araranguá (SC): Universidade Federal de Santa Catarina; 2016. 275 p.

5. Vannucchi, AI. História e Filosofia da ciência: da teoria para a sala de aula (dissertação mestrado em Ensino de Ciências). São Paulo (SP): USP; 1996. 131 p.

6. Ausubel DP, Novak JD, Hanesian H. Psicologia Educacional. Rio de Janeiro: Editora Interamericana; $1980.626 \mathrm{p}$.

7. Ausubel DP. Aquisição e Retenção de Conhecimentos: uma perspectiva cognitiva. Lisboa: Editora Paralelo. 2003. 226 p

8. Moreira MA. Teorias de aprendizagem. São Paulo: EPU. 1999. 248 p.

9. Chevallard Y. La transpostion Didactique - du savoir savant au savoir enseigné. Grenoble: La Pensee Sauvage Éditiona. 1991. 240 p.

10. Alves Filho JP. Atividades Experimentais: Do método à Prática Construtivista (Tese de Doutorado). Florianópolis (SC): Universidade Federal de Santa Catarina; 2000. 302 p.

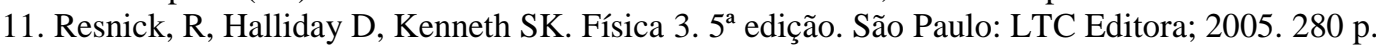

12. Doca RH. Física 3: Eletricidade, Física Moderna e Análise Dimensional. $2^{a}$ Edição. São Paulo: Editora Saraiva; 2013. 400 p. 